\title{
Presupposition and Dissociation in Discourse: A Corpus Study
}

\author{
CHIARA DEGANO \\ Department of Contemporary Languages and Cultures \\ Università degli Studi di Milano \\ p.zza Indro Montanelli 1, Sesto San Giovanni \\ Milan 20099 \\ Italy \\ E-mail: chiara.degano@unimi.it
}

\begin{abstract}
This paper aims at combining different theoretical and methodological approaches for the analysis of discourse, focusing in particular on argumentative structures. At a first level an attempt is made to include argumentation in critical discourse analysis in order to extend the analysis of interaction between "structures of discourse" and "structures of ideologies" to higher levels of language description. At a second level the study will integrate the qualitative approaches of critical discourse analysis and argumentation theory with the quantitative tools of corpus linguistics, so that the analysis can be carried out on a representative amount of texts and in a more systematic way. Even though corpus linguistics tends to be focused on meanings localized at the level of words, while argumentative structures stretch out through longer units of text, an integration can be attempted by circumscribing the enquiry to those aspects of argumentation which are signalled by indicators, and are therefore electronically retrievable. In particular, this paper investigates the use of dissociation and presupposition in a corpus of newspaper articles published in the run up to the war on Iraq. Both structures respond to retrievability criteria while being powerful instruments to convey ideologically oriented messages.
\end{abstract}

KEY WORDS: corpus linguistics, critical discourse analysis, dissociation, presupposition, press, war

\section{INTRODUCTION}

This paper is part of a broader project, which explores the possibility of combining the qualitative approach of critical discourse analysis with the quantitative methodology of corpus linguistics. The aim is to propose an integrated model of analysis which benefits both from the interest of CDA for the modalities through which language represents and constructs reality, and from corpus linguistics' concern for a rigorous description of language, based on a representative sample of data. In particular this paper will give an account of how presuppositions and dissociations were used in the discourse of preparation to the war on Iraq which took shape in the British ${ }^{1}$ press from January 2002, 
when Bush delivered his "axis-of-evil speech", to the outbreak of the war itself, through the analysis of a corpus of newspaper articles ${ }^{2}$ which has been built for the purpose of this study.

The first hypothesis for the present study is that the integrated model I propose can be applied also to higher structures of discourse, such as argumentative moves, which are not so often addressed by CDA, notwithstanding declarations of intents, and even less by corpus linguistics, due to the fact that the typical tools of such discipline are thought to work at best on the level of words and grammar. The choice of presuppositions and dissociations, among all the possible argumentative aspects, is motivated by the fact that they are signalled by words which act as indicators, and are thus retrievable using the tools of corpus linguistics. The second hypothesis is that the occurrence of presuppositions and dissociations in a corpus might signal controversial areas of discourse, where argumentative strategies are more or less covertly used, and therefore worthy of closer qualitative analysis.

\section{MODEL}

The rationale behind the original project results from a double interest: on the one hand there was an epistemological interest for the modalities through which the press represented the debate about the possibility of a war on Iraq, in line with the scope of critical discourse analysis; on the other hand the focus was methodological, and addressed the issue of how corpus linguistics could help to overcome the limits of CDA, which were pointed out in several occasions by different scholars. One first reason of complaint is that the strong political commitment of critical discourse analysts, aimed at unveiling the role of language in maintaining existing power relations to the advantage of dominant groups, has a negative influence in terms of methodological rigorousness (Widdowson, 1995). In particular, some interpretations of the texts are seen to rely more on an ideological basis than on a sound linguistic analysis, and apart from that the relation between discourse and grammar is often uncertain. The second reason concerns the way texts are selected, which often translates into the fact that analyses are carried out on small samples of text which are chosen ad hoc, because they allow to demonstrate pre-constituted interpretative views (Phillips, 1989, p. 8).

As suggested by seminal studies which advocated an integration of qualitative and quantitative approaches (Hardt-Mautner, 1995; Stubbs, 1996; Garzone and Santulli, 2004), the integration of corpus linguistics and CDA could solve both these problems, starting from criteria for text selection. In the first place, the sample of texts and the range of 
sources should be wide enough to be representative of a certain discourse type and the same is true for what concerns the range of sources. Second, when it comes to the analysis of the corpus proper, the quantitative approach forces to a closer observation of data, with a view to the frequency with which a certain characteristic occurs, so that uses which can be identified as recurring are considered as more relevant than isolated examples.

\section{PRESUPPOSITION AND DISSOCIATIONS}

The two structures which have been selected for analysis present a twofold reason of interest. On the one hand, they add to the propositional content, which is explicitly expressed, an evaluative component, which is not physically coded by language, but which is conveyed thanks to the background knowledge and the beliefs shared by the participants. More specifically, this added evaluative component results from the fact that the speaker implicitly attaches different values to related aspects, one being judged more positive or more relevant than the other. Because it is formulated in such a covert way, this form of evaluation is less likely to raise criticism on the part of the reader, and has therefore a high potential for influencing public opinion. With regard to this Thompson and Hunston (2001, p. 9) state that "the less obtrusively the evaluation is placed in the clause, the more likely it is to successfully manipulate the reader". On the same topic, Ducrot $\left(1972\right.$, p. 6) ${ }^{3}$, with reference to presupposition, says:

Every explicit statement becomes, for the very fact of being explicit, an object of possible discussion. All that is stated can be contradicted [...]. The formulation of an idea is the first and decisive step towards it being put into discussion.

On the other hand both presuppositions and dissociations can be retrieved electronically within a corpus of large amounts of texts, because they are associated with specific indicators. Of course, the correspondence between indicator and structure is not automatic, but the output of a query can be scrolled manually, in order to retain only the relevant occurrences. The discussion will now move on to deal with each of the two structures.

\subsection{Presupposition}

A form of pragmatic inference, presupposition is defined by Levinson starting from the meaning the term is given in everyday language, that is "any kind of background assumption against which an action, theory, expression or utterance makes sense or is rational" (1983, p. 168). In a "technical" sense, however, it is possible to talk of presupposition 
only in those cases in which inferences "seem at last to be built into linguistic expressions ${ }^{4}$, and which can be isolated using specific linguistic tests (especially, traditionally, 'constancy under negation')" (Ibidem).

To illustrate how presupposition works, Levinson quotes the example "John managed to stop in time", which presupposes "John tried to stop in time". As for the "constancy under negation" requisite, it is satisfied when the presupposed information stays true even if the verb is negated, as can be seen in the following example:

John didn't manage to stop in time

$\gg$ John tried to stop in time (Ibidem)

However, even if presuppositions are semantically triggered, their meaning potential is not achieved just on the semantic level, but on the contrary the context plays an important role, giving presuppositions a pragmatic value. With reference to the previous example, the presupposition is built into the word "manage", but it is the context, for example the attribution of responsibility in a car accident, which makes this statement relevant and evaluative. Stalkaner (1973, 2002), among others, has emphasised the pragmatic nature, as opposed to the semantic nature, of presupposition. Phenomena such as the wellknown "the present king of France is bald", which presupposes that France has a king, are defined in semantic terms as follows:

A sentence $S$ presupposes that $\varphi$ if and only if $S$ is either true or false only if it is true that $\varphi$.

On the other hand, according to Stalnaker presupposition should be seen as a relation "between a speaker and a proposition" (1973, p. 447) rather than as a relation between propositions themselves, as entailed in the semantic definition. The important aspect is what the speaker takes for granted when s/he uses certain sentences, the background of knowledge or beliefs which s/he thinks is shared by the participants in the communicative exchange. From this perspective, a better definition of presupposition could be as follows:

A speaker presupposes that $\mathrm{P}$ at a given moment in a conversation just in case he is disposed to act, in his linguistic behaviour, as if he takes the truth of $\mathrm{P}$ for granted, and as if he assumes that his audience recognizes that he is doing so (Stalnaker, 1973, p. 448).

The notion of "common ground" outlined in the definition above is considered by Stalnaker the most prominent feature of presupposition since, as he puts it, "one presupposes that $\varphi$ only if one presupposes that others presuppose it as well" (Stalnaker, 2002, p. 701). As we will see later in the section dedicated to the corpus analysis, it was this purportedly shared common ground which was massively exploited in the build up of a case for war. 


\subsubsection{Presupposition analysis}

Different lists of indicators have been drawn, which can be used to spot presuppositions in texts. The analysis of presuppositions in this study was carried out starting form Levinson's selection of "presupposition triggers" (1983, pp. 181-184), which is reported below, focusing only on the ones which recurred more frequently in the corpus:

- Definite descriptions

- Factive verbs

- Implicative verbs

- Change of state verbs

- Iteratives

- Verbs of judging

- Temporal clauses

- Cleft sentences

- Implicit clefts with stressed constituents

- Comparisons and contrast

- Non restrictive relative clauses ${ }^{5}$

- Counterfactual conditionals

- Questions

The analysis of presuppositions that follows aims at understanding what functions they perform in the discourse of preparation to war, with reference to the Hallidayan categories of ideational, textual and interpersonal meaning ${ }^{6}$ (1994). However, while presuppositions can be found to work on all of the three levels, the most interesting uses concern the codification of stance on the level of interpersonal meaning, which subsumes comments, attitudes and values expressed by the writer in the attempt to influence the reader.

The concept of presupposition has been integrated with notions of evaluation theory (Thompson and Hunston, 2001), to make it more suitable for the investigation of ideology in the texts. In particular the analysis revolves around two parameters, one affective, which assigns value in terms of the "good-bad" polarization, the other epistemic, concerning the degree of certainty attached by the speaker to the propositional content of his/her message.

A final preliminary remark needs to be made before passing on to discuss the use of presupposition in the corpus. As mentioned before, many of the articles taken in exam report - as is customary of media discourse - official speeches and statements. This presents the reader with a double level of speakers and, of course, of arguers if some form of argumentative discourse is going on. Since in some cases it might not be clear from the examples who the arguer is, this will be specified as follows: $[\mathrm{S}]$ for the source of the quotation and $[\mathrm{J}]$ for the journalist. 
(i) Presuppositions with an affective evaluative component: Evaluation is expressed most obviously in those presuppositions triggered by verbs with a clear negative connotation, such as verbs of judging. Among these "accuse", some examples of which follow, is the one which occurs most frequently in the corpus:

(1) Mr. Bush has accused Iran of trying to undermine the new regime in Kabul and offering a haven to fleeing Taleban and al-Qaeda fighters. [S] Times

$\gg$ undermining the new regime in Kabul is wrong

(2) Hans Blix, the chief UN weapons inspector, accused both the US and Britain of failing to hand over intelligence on Iraq's activities. [S] Guardian $\gg$ The US and Britain should hand over their intelligence on Iraq's activities.

(3) The official accused the French and Germans of using tactics that rendered Resolution 1441 ineffective. [S] Telegraph

$\gg$ The French and Germans should commit themselves to implement Resolution 1441

(4) Mr. Duncan Smith accused Europe of "gazing at its political navel" while its cities have been coming in range of Middle East missiles. He made clear that a Conservative government would seek to join the United States in developing a global missile defence system. [S] Telegraph

$\gg$ Europe should not "gaze at its political navel"

Apart from presuppositions triggered by explicitly evaluative judgemental verbs, other presuppositions have the effect of expressing value in a less direct way. This is the case when evaluation is not semantically contained in the trigger, but stems from larger stretches of text, as in the following examples:

(5) Mr. Arafat had managed to enforce a ceasefire for three weeks, but there was no diplomatic action to shore it up, as international attention was focused on the trouble in south Asia. [J] Telegraph

$\gg$ he made an effort to enforce a ceasefire

(6) If the pressing concern of America and Britain is the threat posed by Iraq's secret efforts to procure weapons of mass destruction, then a proper course is still to demand the return of the $\mathrm{UN}$ weapons inspections regime. Critics will argue that Saddam managed to hide large sections of his programme from inspectors before they left in 1998. [S] Guardian

$\gg$ Saddam pursued the aim of hiding large sections of his programme

As can be noticed from (5) and (6) the implicative verb "manage" is neither negatively nor positively connotated in itself, but it takes on its value from the negative connotation of the verb which follows. In (5) the presupposition on the one hand can be seen as appreciatory of the effort made by Arafat, but on the other it casts a doubt as to his being 
in control of his people; in (6), since the action of hiding weapons program from the UN inspectors is judged negatively, saying that Saddam "managed" to do that simply adds a negative emphasis on his actions.

(ii) Presuppositions with an epistemic evaluative component: The discussion will now move on to presuppositions with epistemic value, which turned out to be the ones which were deployed most extensively and with the most effective results. Occurrences of epistemic evaluation in the corpus can be mainly divided into two groups: on the one hand those used to present allegation as evidence; on the other the ones which present opinions and judgements as if they were commonly accepted knowledge.

The presuppositions in the first group are principally triggered by factive verbs, verbs which indicate change of state, and iteratives. Here are some examples of the former kind of verbs:

(7) A key question would be whether Saddam was aware of or had sanctioned such a transfer. His special security organisation, run by his son Qusay, has close control over concealed weapons programmes. [J] Telegraph

$\gg$ there was a transfer

(8) Given the latest Bush projections last week - "we know that thousands of trained killers are plotting to attack us" - he must surely have an even more gargantuan cliché up his sleeve. [S] Independent

$\gg$ there are thousands of trained killers ready to attack

(9) Tony Blair reinforced the message yesterday by telling the Commons: "We do know of links between al-Qaida and Iraq. We cannot be sure of the exact extent of those links." [S] Guardian

$\gg$ there are links between al-Qaeda and Iraq.

(10) But we now know that since the departure of the inspectors in 1998, Saddam has bought or attempted to buy specialised vacuum pumps of the design needed for the gas centrifuge cascade to enrich uranium. [S: Blair] Times

$\gg$ Saddam has bought (or tried to buy) vacuum pumps

In all these examples, the factive verb be aware/know presupposes that the object of such knowledge does exist, be it the transfer of weapons from Iraq to Al-Qaeda terrorists in (7), the plots of new attacks in (8), the existence of links between Al-Qaeda and Saddam Hussein in (9), or again the new nuclear programme in (10). However, since they are presupposed, no evidence is put forth to support the claim that all these threats are real. Very often discourses making a case for war reported of intelligence which, for its own nature, could not be fully disclosed: no source could be possibly revealed, and neither could the circumstances whereby the news was apprehended by 
the intelligence services. In these occasions the authoritativeness of the speaker serves as the only guarantee for what is claimed, as is the case in examples 8-10, where Bush or Blair seem to rely on the implicit argument: "you can believe to what I'm saying because I am the president, and I know for sure". A wider extract of Blair's speech reported in (10) will further illustrate this point:

(10a) Saddam's previous nuclear weapons programme was shut down by the inspectors, following disclosure by defectors of the full, but hidden, nature of it. That programme was based on gas centrifuge uranium enrichment. The known remaining stocks of uranium are now held under supervision by the International Atomic Energy Agency. But we now know that since the departure of the inspectors in 1998, Saddam has bought or attempted to buy specialised vacuum pumps of the design needed for the gas centrifuge cascade to enrich uranium; an entire magnet production line of the specification for use in the motors and top bearings of gas centrifuges; dual use products, such as anhydrous hydrogen fluoride and fluoride gas, which can be used both in petrochemicals but also in gas centrifuge cascades; a filament winding machine, which can be used to manufacture carbon-fibre gas centrifuge rotors; and has attempted, covertly, to acquire 60,000 or more specialised aluminium tubes, which are subject to strict controls due to their potential use in the construction of gas centrifuges. In addition, we know Saddam has been trying to buy significant quantities of uranium from Africa, though we do not know whether he has been successful. [S]

Whereas past events concerning WMD are documented through sound verifiable evidence - the previous program was shut down by inspectors and the remaining stocks of uranium are now held under the supervision of the International Atomic Energy Agency -, when it comes to the supposed "new programme", all we are given is a cascade of equipment names (in italics), which would allegedly serve the purpose of enriching uranium. As for the evidence of these new findings, all the epistemic certainty derives from the expression "but we now know".

All these examples contain a fallacy, which consists in the fact that the standpoint that Saddam possesses such weapons is not defended properly. What is violated in this case is the rule of the "burden of proof" (van Eemeren et al., 2002, p. 113) according to which "A party who puts forward a standpoint is obliged to defend it if asked to do so". In political discourse, where no real dialogic exchange is going on, the condition "if asked to do so" should be implicit, since the aim of the speaker is necessarily to influence public opinion and the nature of communication is therefore argumentative. As for the modalities through which such a rule can be violated, in the examples above the burden of proof is avoided by giving one's authority as a guarantee of 
truthfulness, rather than supporting the standpoint with evidence (ivi, p. 116).

Still in relation with Iraq's possession of weapons of mass destruction, predicates of change give rise to presuppositions which represent another kind of fallacy, namely violation of the starting point rule, as explained by van Eemeren et al. (2002, p. 129):

The protagonist violates rule 6 [starting point rule] if he acts as though a certain proposition was accepted as a starting point when that is not the case. A familiar trick for preventing a proposition from being attacked is to formulate something controversial in such an inconspicuous way that it is not noticed. This can be done by presenting the controversial proposition as a presupposition (an assumption tacitly assumed by the speaker) of another statement [...]

In the following examples, the verb "stop" presupposes that the action referred to is actually under way, considering the "reality" of it as an accepted starting point, be it the possession of WMD by what Bush defined "rogue states" $(11,13,14)$ or the relation between "Palestinians" and terrorism (12):

(11) The Bush team is convinced that only the removal of Saddam himself can stop his obsessive efforts to accumulate lethal agents. [S] Telegraph

$\gg$ Saddam is accumulating lethal agents

(12) The second is that the Palestinians must stop encouraging terrorism. This is especially horrifying when it is carried out by teenage girls on a suicide mission. [J] Independent

$\gg$ the Palestinians encourage terrorism

(13) But this morning Mr. Bush said the three nations must stop developing biological, chemical and possibly nuclear weapons or risk US action. [S] Times

$\gg$ the three nations are developing biological, chemical and possibly nuclear weapons

(14) He also wants to stop Iran from funneling arms to terrorists, and seek to prevent North Korea from developing and selling missiles. [S: Bush] Guardian

$\gg$ Iraq funnels arms to terrorists

The same fallacy is generated in presuppositions triggered by iteratives, as exemplified by the following occurrences of the verb "continue":

(15) He needs to continue to make the case for confronting Saddam and eradicating every part of his infrastructure for weapons of mass destruction. [J] Times

(16) My nation will continue to encourage all parties to step up to their responsibilities as we seek a just and comprehensive settlement to the conflict. [S: Bush] Telegraph 
(17) A White House source declined to comment on the draft report in detail, but said: "In general, we have confidence that Mr. Blix will continue to back our view that Saddam has co-operated on process but not on substance. [S] Telegraph

In (15) it is presupposed that Blair ("He") has been making the case for war, whereas one of the leitmotifs in the British press at that time was the lack of a clear "casus belli"; in (16) Bush uses a presupposition to present his foreign policy as equidistant from Palestine and Israel, which is in fact quite disputable, having in several occasion shown a closer bondage with Israel, also in the name of a common fight to terrorism; in the same way, in (17) Blix's communality of opinion with the White House is presupposed as an accepted starting point, whereas the UN Chief Inspector has always highlighted the positive aspect of Iraq's moves of cooperation.

As already pointed out, a second group of presuppositions which can be included under the label of epistemic evaluation presents opinions and judgements as if they were common knowledge. This is best exemplified by the cases where the verb "know" is associated with a plural first person pronoun, which includes the reader, as in the following examples:

(18) Mr. Blair told the committee: "We know perfectly well, I think most of us, that what he said in his declaration of December 8 is not true. [S] Independent

(19) We all know that New Labour is obsessed with manipulation of the news and of its own image. [J] Telegraph

(20) Most Americans know that the administration is acting with moral and historical responsibility. [S] Guardian

In all these cases what is presented as a belief accepted by most people is in fact potentially controversial and far from undisputable. This is demonstrated by the fact that in some of the examples above the purpose is highly polemical since they point out different views shared by competing parties: "we" versus Saddam regime in (18), conservatives and labourists in (19), and more implicitly groups with different positions as to the US Administration in (20).

In this way what is violated is the rule of argumentation scheme, according to which a standpoint may not be regarded as conclusively defended if the defence does not take place by means of an appropriate argument scheme that is correctly applied (van Eemeren et al., 2002, p. 130).

In particular the violation consists in the use of the ad populum argument, the implication of which is that a standpoint should be considered valid simply because many people agree with it, thus running the risk of falling into pure demagogy (ivi, p. 131). 


\subsection{Dissociation}

Originally studied by Perelman and Olbrechts-Tyteca (1958) and more recently by van Rees $(2002,2005)$ dissociation is an argumentative scheme in which the speaker "separates elements that previously were considered by the auditorium as a whole or a conceptual unit" (van Rees, 2005, p. 53). In a more extended definition, which highlights its functional aspect, van Rees (2005, p. 54) explains dissociation as an:

[...] argumentative technique that serves to resolve the contradictions that a notion that originally was covered by a single term and that was considered a unity, gives rise to. Dissociation resolves these contradictions by distinguishing various aspects within that notion, some of which are subsumed under a new denominator. The now reduced old notion and the new notion that has been split off are not equally valued, one is considered more important and more central than the other; therein lies the source of argumentative potential of the technique.

Through a comparison with similar techniques, such as semantic shift, distinction and precisation, van Rees (2005, p. 64) draws three conditions which have to be met in order to identify an argumentative move as dissociation:

1. from an existing conceptual unit, expressed by a single term, one or more aspects are split off; 2. through this operation a contradiction or paradox is resolved because now a proposition can be considered true in one interpretation of the original term and false in the other; 3 . the reduced and the split off concept are assigned a different value.

On the basis of these features, van Rees finds some possible indicators of dissociation, which can be identified as clues of separation, with reference to feature 1 , clues of negation, in touch with feature 2 and reference to a value scale, according to feature 3. The first group includes words and expressions that signal a distinction or a form of precization, such as "distinction", "difference", "not the same as", "something else than", "except", "precizate" etc. The second group entails all the indicators of opposition, and most notably the negative adverb "not", in particular when associated with the conjunction "but". Indicators of the third group, finally, point to a different value attribution to the two elements which result from the dissociation of the former unified concept. These include words which can be referred to value scales such as "essential-incidental", "central-peripheral", "real-pseudo", etc. In some cases the dissociation is performed explicitly, while in others a part of the process remains unexpressed and is taken as a "self evident starting point" (ibidem).

In real use, however, it is not always possible to distinguish clearly whether dissociation is originated by a process of separation, negation or attribution of different values on a given scale, as it is often the case that more than one process is in progress. Therefore, even though the cases of dissociation which follow were retrieved in the corpus 
starting from indicators of the three groups ${ }^{8}$, the discussion will not be organised on the basis of the type of indicator. Instead, examples will be grouped together on the basis of patterns of meaning which a data driven analysis has revealed as being recurrent.

\subsubsection{Analysis of dissociations in the corpus}

Two main uses of dissociation emerge from the corpus: a polemical use aimed at presenting this war as anomalous in various respects, and a defensive use adopted by those who are against it in order to defend their position from the attacks of war supporters. For what concerns the first group, an example can be found in the following fragment:

(21) Why won't the Government tell us whether it thinks military action against Iraq would be lawful in the absence of an explicit resolution from the United Nations Security Council? Tony Blair and his ministers have repeatedly said anything they may do will be in accordance with international law. That sounds reassuring, but only until you remember that international law is not like other law. As Ross Cranston, an academic lawyer and former Labour law officer, said in the Commons this week: "One of the difficulties with international law, as opposed to domestic law, is that no body has jurisdiction over the whole range of issues." [J] Telegraph

The speaker separates international law from other law assigning a diminished value to the former to demonstrate that Blair's words cannot be reassuring. The speaker's implicit standpoint is that in his opinion, the British premier would be ready to back a US war even without a UN resolution, and this would be illegal. Blair's statement that any action would be in accordance with International law seems to be in contradiction with the speaker's standpoint, but the dissociation allows to solve this problem, by presenting international law as defective: if normally the fact that an action abides by a law can be seen as a guarantee of its equity, this is not the case with international law.

In the following example the explicit opposition these times - normal times points to a more indirect opposition, concerning the UN draft resolution about Iraq:

(22) The draft resolution goes further than previous UN directives in imposing the kind of intrusive rules, regulations and timetables that any sovereign nation, in normal times, would reject out of hand. The US, for example, has stubbornly resisted international inspections of its biological weapons facilities. Israel, for example, has unknown, undeclared stockpiles of weapons of mass destruction. But these are not normal times. [J] Guardian 
In this case it is more difficult to spot a dissociative move, because most of the reasoning is implicit. The focus of discussion is on the draft resolution and indirectly on its effects in terms of the possible Iraqi reaction. It is foreseen that Saddam's reaction will not be of compliance, but the position of the speaker is that he can't be blamed for that. This could give rise to a contradiction, because in Western democracies it is customary to believe that not complying with UN resolutions is wrong. However this is resolved by separating this resolution, which is the output of "these times", from the resolutions of "normal times": while in normal times resolutions respect national sovereignty, in this case it imposes rules, regulations and timetables that any sovereign nation would normally reject, therefore it cannot be expected that Iraq will be an exception.

In a similar way, also the next fragment presents the contemporary situation as anomalous, and therefore as requiring new measures:

(23) The Divisional Court concluded that it had no jurisdiction to consider the issue of international law. It was plainly correct to do so as a matter of constitutional law. As pointed out by Lord Justice Simon Brown (with whom Mr. Justice Maurice Kay and Mr. Justice Richards agreed), it is wellestablished that the courts will not declare the meaning of an international agreement that is not part of domestic law. On the basis of high judicial authority, the Divisional Court had no choice but to reject the CND claim.

But should the courts refuse to entertain such a complaint? The Divisional Court gave three main reasons why the courts decline to be involved, none of them very persuasive. The first was the evidence from the Foreign Office that if the Government were obliged to answer international law arguments, it may undermine the prospects of a diplomatic solution to the crisis, "damage our relations with the US" and "give comfort to the Iraqis". But the Government would be responding on issues of law, not policy or strategy.

The Divisional Court's refusal to consider the substance of the case was correct on the existing precedents. But it is time for legal policy to be reconsidered. [J] Times

With reference to the conclusion of the Divisional Court that "it had no jurisdiction" to express itself on the lawfulness of a war on Iraq without a UN resolution, the dissociation, is performed by separating the notion of "correct on the existing precedents" from the notion of uncompromisingly "correct", where clearly the newly separated notion is assigned a diminished value. In this way the speaker can argue that the decision of the court was not the best, even if it was in accordance with the law, while at the same time he advocates a change in the current legislation, motivated by the changes in the international political situation. 
The next fragment presents another anomalous aspect related to the war on Iraq, that is the nature of the "new" terrorism, and two dissociative moves:

(24) Not only is the message not getting across, but there seems to be a fundamental misunderstanding of where the real sophistication of Jihad International comes from. It is not in its ingenious and despicable skill in butchering innocent civilians, or even in its apparently formidable organisational skills, which in reality may be far less formidable than assumed, but in syndicating and marketing its brand of terror. This is not the old terrorism of the IRA or ETA, with structures, doctrines and pseudo-military organisation. What Bush and Blair and all their allies do not understand is that it is the idea of al- Qaeda, not its physical reality, that is the key, an idea which has taken deep root in countries from Afghanistan to South East Asia and Africa. [J] Guardian

First of all, the expressions "misunderstanding" and "real sophistication" are indicators of a process of dissociation. Since it cannot be denied that ingeniousness and skill in the preparation of attacks are among the characteristics of al-Qaeda, the speaker, who wants to make the point that something else, i.e. the ability in "marketing its brand of terror", is at the basis of the terrorist organization's "success", distinguishes "real sophistication" from a more marginal kind of sophistication. A second dissociation reinforces the speaker's line of argument: the previously unified concept of al-Qaeda is split off into two new concepts, its physical reality, and its idea. In this way, it can be argued without contradiction that the widespread conception about al-Qaeda, shared by Bush, Blair and all their allies, is right if limited to the organization's physical reality, while it does not seize the real force of the organization, which lies in its idea and which is well rooted in many countries.

As mentioned before, a second pattern related to dissociation reveals that this technique is used with a defensive function, to negate that one party's position is in some way contradictory, as suggested by the other party. In particular this form of dissociation was exploited by those who were against the war, but did not want to be seen as supporters of the Iraqi regime, as in the next example:

(25) In yesterday's speech Mr. Blair widened his case in an attempt to appease rebellious members of his party. As well as making the familiar global arguments about the need to disarm Saddam, he put the moral "progressive" arguments for the removal of the Iraqi regime. This was the clearest sign that $\mathrm{Mr}$. Blair is rattled by the scale of the internal opposition. He cited the atrocities committed by Saddam and warned of the potential horrors if there were no war against Iraq. The Independent on Sunday is a progressive newspaper, but we do not accept this argument as a justification 
for a pre-emptive strike against another country. As we have argued for several months, President Bush and Mr. Blair have to convince voters that Iraq poses a real and immediate threat. Their failure to do so is the reason why Mr. Blair faces the biggest political crisis of his career. [J] Independent

In this case a double use of implicit dissociation is made. On the one hand Blair's recourse to the "moral progressive argument" for the removal of Saddam Hussein relies on a submerged dissociation. Confronted by his own party's opposition, Blair finds himself in the potentially contradictory position of being progressive and being at the same time in favour of a war. By means of an implicit dissociation he can defend war for humanitarian reasons and reject "offensive" wars thus staying true to progressive values. At the same time Blair seems to imply that those who claim to be progressive but are not ready to defend the human rights of the Iraqi people are not really progressive. On the other hand, the Independent on Sunday defends itself from such an accusation by separating the notion of "accepting the progressive argument for a pre-emptive war" from the notion of "being progressive", which allows them to reject the former and assert the latter.

In a similar way, the next fragment can be seen as an attempt to escape a polarizing argument:

(26) No doubt there are some abroad who support Saddam, others who are neutral and others who want to see him go but do not think an American war is the way to do it. [J] Guardian

Here the Guardian is making the point that there is no contradiction in being against Saddam and at the same time against a war on Iraq. Implicitly the writer splits off the concept of a dictator's removal distinguishing between the principle underlying it and the way it is effected, so that the newspaper can hold its position of being in favour of the principle, but against the war as a way to achieve this objective.

The same happens in the next example, where the dissociation concerns the concept of "supporting America"

(27) Only 19\% believe Britain should join America in military action. Almost the same proportion, $17 \%$, believe that the British government should publicly condemn America if it takes unilateral action. In between, a large majority believe Britain should either "support America diplomatically but not militarily" (32\%) or else "distance itself from America but not condemn it" $(29 \%)$. YouGov's findings hint at the possibility that considerable numbers of Britons would like to see America bear the heat of the day and, with luck, successfully toppling Saddam Hussein, with Britain remaining comfortably on the sidelines. [S] Telegraph

One of the possible answers to the items of a questionnaire separates the notions of diplomatic support and military support to the 
US, thus giving the interviewee a chance to escape the "pro-war or pro Saddam" moral blackmail, while at the same time solving the contradiction which would come from the decision of denying support to an ally.

Finally a last example will be discussed, which does not pertain to any of the two patterns of dissociation use presented so far, but which is in its own representative of a highly manipulative line of argument in support of war:

(28) "These are not people like us," he said of the Iraqi leadership on Sunday. "They are not people who abide by the normal rules of human behaviour". [S: Blair] Guardian

Here Blair places the Iraqi leaders outside the domain of humanity, which is implicitly and in a rather circular fashion redefined as the community of those who "abide by the norms of human behaviour". This way of reasoning is in itself potentially dangerous in ethical terms for the perspectives it could open up, but it also hints at a likewise dangerous dissociation which pervasively underpinned the pro-war discourse, that is the artificial distinction between Iraqi leaders and Iraqi people. On this basis the war was massively presented as directed exclusively against Saddam's regime, in favour of the Iraqi people. However, whereas such a distinction might be legitimate if one wanted to make the point that the majority of the Iraqi population did not feel represented by Saddam's regime, it is much less so if used to divert attention from the fact that a war would hit the population as well as its leadership.

\section{CONCLUSIONS}

For this paper I set a double aim: from a theoretical point of view I addressed the issue of the possibility to integrate critical discourse analysis, with its typically qualitative approach, Corpus linguistics, which on the other hand relies on quantitative methodology and argumentation theory, which I hypothesized could help to extend the analysis to higher structures of discourse. On a more operative level, I applied this model in the analysis of the discourse produced by the British press in preparation of the war in Iraq, focusing on presuppositions and dissociations, two discursive structures which have an argumentative potential and at the same time can be retrieved electronically thanks to the presence of possible indicators.

On this second level the analysis dealt in turn with the two structures, following essentially a data driven approach, which aimed at highlighting recurrent patterns of use. For what concerns presuppositions, they 
were discussed in relation to the kind of evaluation they express, both of affective and epistemic nature. While presuppositions of the first kind confirmed that this structure is a good starting point for the analysis of ideology in discourse, the most interesting results came from presuppositions of the second kind. What emerged is that they were extensively used to refer to weapons of mass destruction, with the effect that Iraq's possession of illegal weapons was generally taken for granted and it rarely became the focus of explicit argument. Also some fallacies were identified, in relation to the use of presuppositions.

For what concerns dissociations, two patterns emerged, which confirmed the highly argumentative potential of this technique. On the one hand they were used with a critical intent to highlight anomalous aspects of this war, which responded to new political doctrine of preemptive attack. On the other hand they were used by those who rejected the option of war, to defend themselves from the accusation of being in favour of a brutal regime and of terrorism.

In the light of the results presented in this paper, it can be concluded that corpus linguistics' tools can be profitably integrated with critical discourse analysis and argumentation theory into a model for the analysis of discourse structures.

\section{NOTES}

1 The corpus includes both British and Italian newspapers for a total of 800 articles. This paper, however, takes into account only the British quality newspapers sub-corpus.

${ }^{2}$ Both news reports and comment articles form the corpus. The decision of considering both types of texts was motivated by the belief that this would render a more representative picture of the discourses produced by the press in the run-up to the war. Apart from that, it seemed in tune with one of the tenets of critical discourse analysis, i.e. the belief that ideology is implicitly codified into linguistic choices, and therefore it is not limited to opinion articles in media discourse. This was even more so in the period taken into account, since most of news reports then referred to speeches and statements of politicians, rather than to real events, allowing for a good amount of opinion expression, either implicitly or explicitly. However the nature of the articles (comment or report) has never been employed as a variant in the analysis, since they are not evenly distributed within the corpus. When collecting the corpus, it was decided that the main criteria for news selection would be chronological, (i.e. articles would be selected at regular intervals of time), disregarding whether on the established day both reports and comments would be available. Therefore no generalisation can be drawn about the distribution of linguistic phenomena across the two kinds of texts.

3 My translation.

4 The fact of being "built into linguistic expressions" makes presupposition different from implicature, another form of pragmatic inference, which requires higher cooperation by the reader in order to be interpreted correctly.

5 Although the notion that non restrictive relative clauses can generate presuppositions is not undisputed (Lombardi-Vallauri, 2002, p. 24), in this study they are considered presupposition triggers, resting on Levinson (1983, pp. 181-184). 
${ }^{6}$ The three categories are referred to the levels of meaning which can be codified in text. The first concerns informative content, the second deals with metadiscursive content and the third with the expression of stance.

${ }^{7}$ This is with reference to the rules for critical discussion outlined by van Eemeren et al. (2002, pp. 109-139). The list includes ten rules, distributed across the four stages of critical discussion, which should be followed in order to resolve a dispute through valid reasoning according to the critical discussion model. Any violation of these rules constitutes a fallacy. From this perspective, fallacies are redefined in a procedural way, as opposed to the traditional "moral" conception, and their list is systematized.

${ }^{8}$ Concordances were extracted automatically for each indicator, and then the output lines were considered one by one in a traditional way, in order to single out the cases of dissociation. This process resulted in the elimination of most of the concordance lines, but in some cases traditional 'manual' analysis allowed to identify cases of implicit dissociation which were not signalled by indicators, but which just happened to be visualised on the concordance list because they contained the query word, even though such word was not used as an indicator of dissociation in that case.

\section{REFERENCES}

Ducrot, O.: 1972, Dire et ne pas dire, Hermann.

van Eemeren, F. H., R. Grotendorst and A. F. Snoeck Henkemans: 2002, Argumentation: Analysis, Evaluation, Presentation, Lawrence Erlbaum, Mahwah, NJ.

Garzone, G. and F. Santulli: 2004, 'What Can Corpus Linguistic Do for Critical Discourse Analysis?', in A. Partington, J. Morley and L. Haarman (eds.), Corpora and Discourse, Peter Lang, Bern, pp. 351-368.

Halliday, M. A. K.: 1985, 1994, An Introduction to Functional Grammar, 1st and 2nd editions. Edward Arnold, London.

Hardt-Mautner, G.: 1995, Only Connect. Critical Discourse Analysis and Corpus Linguistics, UCREL, Lancaster.

Levinson, S. C.: 1983, Pragmatics, Cambridge University Press, Cambridge.

Lombardi-Vallauri, E.: 2002, La struttura informativa dell'enunciato, La Nuova Italia, Milano.

Perelman, C. and L. Olbrechts-Tyteca: 1958, Traité de l'argumentation. La nouvelle rhetorique, Presses Universitaires de France, Paris.

Phillips, M. A.: 1989, 'Lexical Structure of Text', Discourse Analysis Monograph 12. English Language Research, Birmingham.

van Rees, M. A.: 2002, 'Argumentative Functions of Dissociation in Every-day Discussions', in H. V. Hansen, C. W. Tindale, J. A. Blair, R. H. Johnson and C. Pinto (eds.), Argumentation and its Applications, OSSA 2001, CD-rom.

van Rees, M. A.: 2005, 'Indicators of Dissociation', in F. H. Eemeren and P. Houtlosser (eds.), Argumentation in Practice, Benjamins, Amsterdam, pp. 53-68.

Stalnaker, R.: 1973, 'Presuppositions', Journal of Philosophical Logic 2, 447-457.

Stalnaker, R.: 2002, 'Common Ground', Linguistics and Philosophy 25, 701-721.

Stubbs, M.: 1996, Text and Corpus Linguistics, Blackwell, Oxford.

Thompson, G. and S. Hunston: 2001, 'Evaluation: An Introduction', in S. Hunston and G. Thompson (eds.), Evaluation in Text, Oxford University Press, Oxford, pp. 1-27.

Widdowson, H. G.: 1995, 'Discourse Analysis: A Critical View', Language and Literature 4(3), 157-172. 